\title{
Sementes de milho doce tratadas: substratos para o teste de germinação e sanidade
}

\author{
Treated sweet corn seeds: substrates for germination and health testing \\ Semillas de maíz dulce tratadas: sustratos para germinación y pruebas sanitarias
}

Recebido: 22/09/2021 | Revisado: 01/10/2021 | Aceito: 13/10/2021 | Publicado: 16/10/2021

\author{
Isabela da Rosa Bersch \\ ORCID: https://orcid.org/0000-0002-6698-5362 \\ Universidade Federal de Pelotas, Brasil \\ E-mail: isa1_rosa@yahoo.com.br \\ Josiane Cantuária Figueiredo \\ ORCID: https://orcid.org/0000-0001-7105-1241 \\ Universidade Federal de Pelotas, Brasil \\ E-mail: josycantuaria@yahoo.com.br \\ Cristina Rossetti \\ ORCID: https://orcid.org/ 0000-0003-2772-5952 \\ Universidade Federal de Pelotas, Brasil \\ E-mail: cristinarossetti@yahoo.com.br \\ Jacqueline Barcelos da Silva \\ ORCID: https://orcid.org/0000-0003-4154-0081 \\ Universidade Federal de Pelotas, Brasil \\ E-mail: jackelinecnj@hotmail.com \\ Andréia da Silva Almeida \\ ORCID: https://orcid.org/0000-0003-3169-6787 \\ Universidade Federal de Pelotas, Brasil \\ E-mail: andreiasalmeida@yahoo.com.br \\ Daniele Brandstetter Rodrigues \\ ORCID: https://orcid.org/0000-0003-3600-0320 \\ Universidade Federal de Pelotas, Brasil \\ E-mail: ufpelbrandstetter@hotmail.com
}

\section{Resumo}

Resultante de uma mutação espontânea do milho convencional, o milho doce possui elevado potencial de produtividade no Brasil, sendo considerado alternativa rentável aos produtores, e o colocando em ascensão. Contudo, a escassez de informações técnicas reduz este avanço. A fim de analisar a viabilidade da semente, o teste de germinação em laboratório é utilizado para comparar a qualidade entre lotes e estimar seu desempenho para semeadura em campo. Suscetível ao ataque por fungos e insetos, devido sua composição e características morfológicas, o tratamento de sementes de milho doce com produtos químicos é uma opção viável para reduzir possíveis perdas de qualidade. Desse modo, analisou-se a incidência de fungos fitopatogênicos, bem como sua redução devido ao uso de fungicidas no TS. Porém, para o teste de germinação, pode-se encontrar antagonismo do valor obtido para sementes tratadas, relacionado ao desempenho destas sementes a campo. A fim de elucidar e corrigir estes erros realizou-se um estudo das condições que os propiciam e definiram-se soluções para o problema, adequando às metodologias utilizadas na realização dos testes de germinação.

Palavras-chave: Zea mays L.; Tratamento; Teste de germinação; Viabilidade.

\begin{abstract}
Resulting from a spontaneous mutation of conventional corn, sweet corn has high productivity potential in Brazil, being considered a profitable alternative for producers, and putting it on the rise. However, the scarcity of technical information reduces this advance. In order to analyze the viability of the seed, the laboratory germination test is used to compare the quality between lots and to estimate their performance for sowing in the field. Susceptible to attack by fungi and insects, due to its composition and morphological characteristics, the treatment of sweet corn seeds with chemicals is a viable option to reduce possible quality losses. In this way, the incidence of phytopathogenic fungi was analyzed, as well as their reduction due to the use of fungicides in the TS. However, for the germination test, one can find antagonism of the value obtained for treated seeds, related to the performance of these seeds in the field. In order to elucidate and correct these errors, a study of the conditions that provided them was carried out and solutions to the problem were defined, adapting to the methodologies used in the germination tests.
\end{abstract}

Keywords: Zea mays L.; Treatment; Germination test; Viability. 


\begin{abstract}
Resumen
Como resultado de una mutación espontánea del maíz convencional, el maíz dulce tiene un alto potencial de productividad en Brasil, siendo considerado una alternativa rentable para los productores y poniéndolo en alza. Sin embargo, la escasez de información técnica reduce este avance. Para analizar la viabilidad de la semilla, la prueba de germinación de laboratorio se utiliza para comparar la calidad entre lotes y estimar su rendimiento para la siembra en campo. Susceptible al ataque de hongos e insectos, por su composición y características morfológicas, el tratamiento de semillas de maíz dulce con productos químicos es una opción viable para reducir posibles pérdidas de calidad. Así, se analizó la incidencia de hongos fitopatógenos, así como su reducción por el uso de fungicidas en el ST. Sin embargo, para la prueba de germinación, se puede encontrar un antagonismo del valor obtenido para las semillas tratadas, relacionado con el desempeño de estas semillas en el campo. Con el fin de dilucidar y corregir estos errores, se realizó un estudio de las condiciones que los proporcionan y se definieron soluciones al problema, adecuándose a las metodologías utilizadas en la realización de las pruebas de germinación.
\end{abstract}

Palabras clave: Zea mays L.; Tratamiento; Prueba de germinación; Viabilidad.

\title{
1.Introdução
}

O milho doce (Zea mays L. grupo saccharata) pertencente à família poaceae, resulta de uma mutação espontânea do milho convencional. Diferindo-se, principalmente, pelos teores de açúcar e amido dos grãos (Bhatt et al., 2012). Conceituado uma hortaliça de alto valor nutricional e comestível, pois é rica em açúcar, diversos aminoácidos, vitaminas, minerais e fibra alimentar (Aziz et al., 2019; Yang et al., 2018).

Seu elevado potencial produtivo e perspectiva de mercado o caracterizam como boa opção de cultivo para os produtores. Porém, o desconhecimento e escassez de informações técnicas reduz seu avanço (Cruz, 2014).

Somando à escassez de informações técnicas, suas características químicas e genéticas a desfavorecem quando o tópico é qualidade fisiológica de sementes, especialmente em relação ao armazenamento. Sementes de milho doce apresentam rápida perda de viabilidade e suscetibilidade ao ataque de fungos e insetos devido sua composição química e morfologia, reduzindo drasticamente a qualidade final. Logo, o tratamento de sementes é um dos mais rentáveis e adequado método de controle, pois protege as sementes desde a semeadura, desempenhando papel fundamental para o sucesso da emergência de plântulas de maneira uniforme em condições normais ou adversas (Oliveira, 2016).

O teste de germinação para sementes de milho (Zea mays L.) padronizado nas Regras de Análises de Sementes (Brasil, 2009) indica a utilização de substrato RP (rolo de papel) ou EA (entre areia), submetidas as temperaturas constantes de $20^{\circ}, 25^{\circ}$ ou $30^{\circ} \mathrm{C}$ e/ou temperatura alternada de $20-35^{\circ} \mathrm{C}$. No entanto, é ausente de padronização do teste para sementes de Zea mays $L$. grupo saccharata em específico, que por tratarem-se de sementes com baixo potencial fisiológico e menor germinação quando comparadas as de milho comum, requerem atenção e especificações para que o resultado possa ser considerado satisfatório.

Além disso, a colonização destas sementes por fungos pré e pós-colheita é favorecida pelo alto teor de açúcares solúveis no endosperma e aberturas no tegumento de suas sementes secas (Gomes Junior, 2009), sendo necessário o tratamento dessas sementes com produtos químicos, nesse caso, fungicidas e inseticidas. Contudo, existem dúvidas sobre a reprodutibilidade da metodologia tradicional para avaliação de germinação de sementes tratadas, em razão disso, há necessidade de adequações dessa metodologia para garantir um resultado confiável do laboratório de análise de sementes, pela expressividade do teste para comercialização.

De acordo com o tipo de material utilizado, fatores como estrutura, aeração, capacidade de retenção de água e grau de infestação de patógenos, podem variar, logo, a utilização de diferentes substratos como o rolo de papel; o rolo de papel + areia; o rolo de papel + vermiculita e areia em bandejas (entre areia) influenciam significativamente os resultados. Desse modo, é de suma importância a uniformização da metodologia com relação ao substrato, considerando a presença do tratamento químico mais adequado. 
Assim sendo, com o presente estudo o objetivo foi analisar diferentes produtos presente no mercado, nos substratos indicados pela RAS para o teste de germinação, e também testar substratos alternativos ao uso do rolo de papel e germinação entre areia, verificando ainda, a incidência de fungos.

\section{Metodologia}

O experimento foi conduzido no Laboratório de Ciência e Tecnologia de Sementes (Dpto. de Fitotecnia), e no Laboratório de Patologia de Sementes (Dpto. de Fitossanidade), ambos pertencentes à Universidade Federal de Pelotas campus Capão do Leão -RS. Foram utilizadas sementes de milho doce, com germinação superior a 65\%.

O delineamento experimental utilizado foi o inteiramente casualizado, sendo os tratamantos compostos por quatro produtos químicos para o tratamento das sementes (Fortenza 600 FS (inseticida); Standak top (fungicida/inseticida); Cruiser 350 FS (inseticida) e Maxim XL (fungicida)) + testemunha (semente sem tratamento) (Tabela 1).

Tabela 1. Produtos comerciais, doses e volumes de calda final para cada tratamento de sementes de milho doce.

\begin{tabular}{|c|c|c|c|}
\hline Ingrediente Ativo (i.a.) & Nome comercial & Dose utilizada & $\begin{array}{c}\text { Volume de água } \\
(\mathrm{mL})\end{array}$ \\
\hline Testemunha & & 0 & 0 \\
\hline Ciantraniliprole & Fortenza 600 FS & $350 \mathrm{~mL} / 100 \mathrm{~kg}$ de sementes & 150 \\
\hline $\begin{array}{l}\text { Piraclostrobina + Tiofanato } \\
\text { metílico+ Fipronil }\end{array}$ & Standak top & $250 \mathrm{~mL} / 100 \mathrm{~kg}$ de sementes & 250 \\
\hline Tiametoxam & Cruiser $350 \mathrm{fs}$ & $120 \mathrm{~mL} / 60.000$ sementes & 380 \\
\hline Metalaxil-M + Fludioxonil & Maxim XL & $150 \mathrm{~mL} / 100 \mathrm{~kg}$ de sementes & 350 \\
\hline
\end{tabular}

Fonte: Adapar, consulta em 26/10/2020.

Foi utilizado $0,250 \mathrm{~kg}$ de semente por tratamento, sendo a calda (produto + água) aplicada com o auxílio de uma pipeta graduada, no fundo de um saco plástico transparente e distribuída pelas paredes do saco. O volume de calda utilizado foi de 0,5 L.100 $\mathrm{kg}^{-1}$ de sementes, ajustada à dose máxima recomendada (Tabela 1). Após o tratamento, as sementes foram colocadas à sombra a uma temperatura de aproximadamente $25^{\circ} \mathrm{C}$ por um período de 60 minutos para secagem do produto na superfície da semente. Em seguida as sementes foram avaliadas pelos seguintes testes:

Teste de germinação: foi realizado utilizando metodologia preconizada pelas RAS e metodologias alternativas, utilizando oito repetições de 50 sementes para cada tratamento.

Substrato papel Germitest ${ }^{\circledR}$ : as sementes foram semeadas em substrato umedecido com água destilada no volume de 2,5 vezes o peso do papel seco, e mantido na forma de rolo em germinador digital previamente regulado à temperatura constante de $25^{\circ} \mathrm{C}$ e fotoperíodo constante (Brasil, 2009).

Substrato areia: a semeadura das sementes foi realizada a uma profundidade de $1,5 \mathrm{~cm}$, em bandejas plásticas, contendo o substrato umedecido com quantidade de água destilada equivalente a $60 \%$ da capacidade de retenção (Brasil, 2009). As bandejas foram colocadas em germinador digital previamente regulado à temperatura constante de $25{ }^{\circ} \mathrm{C}$ e fotoperíodo constante (Brasil, 2009).

Substrato papel Germitest ${ }^{\circledR}+$ areia: as sementes foram semeadas em papel germitest contendo 17,5 gramas de areia autoclavada e umidecida com quantidade de água destilada equivalente a $60 \%$ da capacidade de retenção, em seguida foram confeccionados rolos e estes mantidos em germinador digital previamente regulado à temperatura constante de $25{ }^{\circ} \mathrm{C} \mathrm{e}$ fotoperíodo constante. 
Substrato papel Germitest ${ }^{\circledR}$ + vermiculita: as sementes foram semeadas em papel germitest contendo 17,5 gramas de vermiculita umidecida na proporção de $1 \mathrm{~L}$ de água para cada $1 \mathrm{~kg}$ de substrato (vermiculita), em seguida foram confeccionados rolos e estes mantidos em germinador digital previamente regulado à temperatura constante de $25^{\circ} \mathrm{C}$ e fotoperíodo constante.

A avaliação da germinação foi realizada ao sétimo dia após a semeadura, cujos resultados foram expressos em porcentagem de plântulas normais, de acordo com Brasil (2009).

Primeira contagem de germinação: realizada conjuntamente com o teste de germinação, contabilizando-se as plântulas normais presentes no quarto dia após a semeadura (Brasil, 2009).

Emergência de plântulas a campo: o teste foi realizado com 200 sementes por tratamento, divididas em quatro repetição de 50 sementes, distribuídas em sulcos com $3 \mathrm{~cm}$ de profundidade, dispostas em linhas com $20 \mathrm{~cm}$ de espaçamento entre linhas e $5 \mathrm{~cm}$ entre sementes. A contagem foi realizada aos 14 dias após a semeadura, quando ocorreu a estabilização da emergência das plântulas considerando apenas as que emitiram o coleóptilo acima da superfície do solo.

$O$ índice de velocidade de emergência: foi conduzido em conjunto com o teste de emergência de plântulas, contabilizando-se diariamente, o número de plântulas emergidas até o final do teste. Com os dados obtidos, o índice de velocidade de emergência foi calculado empregando-se a fórmula proposta por Maguire (1962).

Patologia de sementes: a avaliação da incidência dos fungos fitopatogênicos ocorreu por meio da incubação das sementes pelo método "Blotter Test" (Brasil, 2009). Para tanto, foram utilizadas 200 sementes por amostra, distribuídas em 8 repetições de 25 sementes, dispostas em caixas Gerbox ${ }^{\circledR}(11 \times 11 \times 3,5 \mathrm{~cm})$ contendo duas folhas de papel de filtro (mata-borrão) umedecido com água destilada e, posteriormente, incubadas sob fotoperíodo de 12 horas de luz/12 horas de escuro a uma temperatura de $22^{\circ} \mathrm{C} \pm 3^{\circ} \mathrm{C}$ durante sete dias (Brasil, 2009). Com base na morfologia dos conídios e na arquitetura conídio/conidióforo sob microscópio estereoscópico e microscópio ótico, quando necessário, procedeu-se à identificação dos patógenos. Os resultados foram expressos em porcentagem de fungos.

Os dados foram testados quanto à normalidade e homogeneidade de variâncias e, após atenderem a esses pressupostos, foram submetidos à análise de variância, sendo as médias comparadas pelo teste Tukey a 5\% de probabilidade utilizando o programa Winstat.

\section{Resultados e Discussão}

Na Tabela 2 estão os resultados do teste de germinação conduzido de acordo com os padrões pré-estabelecidos nas Regras para Análise de Sementes (RAS), com o percentual de plântulas normais, conduzido com uma temperatura constante de $25^{\circ} \mathrm{C}$. A porcentagem de sementes de milho doce tratadas quimicamente germinadas submetidas ao teste no substrato rolo de papel (RP) não diferiu significativamente entre tratamentos, obtendo valores satisfatórios para todos tratamentos. Logo, verifica-se que o substrato rolo de papel (RP) é adequado para realização do teste de germinação de sementes de milho doce tratadas.

Sendo $65 \%$ de germinação o limite mínimo tolerado para comercialização de sementes certificadas de milho doce, o substrato entre areia (EA) somente satisfaz a exigência limítrofe para testemunha, ou seja, sementes ausentes de tratamento com produto químico, não havendo diferença significativa entre tratamentos (Tabela 2). Portanto, diverge dos resultados do substrato rolo de papel, também padronizado e disposto nas Regras para Análise de Sementes (RAS), verifica-se que o substrato areia não é adequado para realização do teste de germinação de sementes de milho doce tratadas. Considerando que foi realizado igualmente ao rolo de papel, sob condições artificiais controladas de laboratório, altamente favoráveis, para que se obtenha a maior porcentagem de germinação.

Desse modo, para fins comerciais, a adoção de um procedimento padrão na instalação do teste de germinação de sementes tratadas, condução e avaliação dos substratos permite a obtenção de resultados comparáveis entre laboratórios de 
empresas fornecedoras e compradoras de sementes (ISTA, 2011). Assim, o teste é realizado com algumas adaptações da metodologia padronizada (Brasil, 2009), controlando fatores bióticos e abióticos, a fim de permitir que as sementes expressem todo seu potencial fisiológico.

Tabela 2. Germinação (\%) provenientes de sementes tratadas quimicamente submetidas ao teste de germinação nos padrões das Regras para Análise de Sementes (RAS).

\begin{tabular}{ccc}
\hline \multirow{2}{*}{ Tratamentos } & \multicolumn{2}{c}{ Substrato } \\
\cline { 2 - 3 } & Rolo de Papel (RP) & Entre Areia (EA) \\
\hline Testemunha & $76 \mathrm{~A}$ & $65 \mathrm{~A}$ \\
Fortenza 600 FS & $80 \mathrm{~A}$ & $54 \mathrm{~A}$ \\
Standak top & $85 \mathrm{~A}$ & $61 \mathrm{~A}$ \\
Cruiser 350 FS & $78 \mathrm{~A}$ & $59 \mathrm{~A}$ \\
Maxim XL & $79 \mathrm{~A}$ & $64 \mathrm{~A}$ \\
\hline
\end{tabular}

*Na coluna, médias seguidas da mesma letra maiúscula não diferem significativamente entre si, pelo teste de Tukey, a 5\% de probabilidade. Fonte: Autores.

$\mathrm{Na}$ Tabela 3 estão os resultados do teste de germinação, incluindo os substratos alternativos, expressos em percentual de plântulas normais, conduzido com uma temperatura constante de $25^{\circ} \mathrm{C}$. Os testes de germinação com o uso dos substratos rolo de papel; rolo de papel + areia e rolo de papel + vermiculita para sementes tratadas com Standak top apresentaram valores semelhantes nos percentuais de plântulas normais, quando comparado aos demais tratamentos e testemunha, valores estes considerados supra ótimos, atingindo $86 \%$ para semeadura em rolo de papel + vermiculita. O substrato rolo de papel + areia obteve percentual de plântulas normais mais acentuado para sementes tratadas com Standak top e Cruiser 350 FS. No entanto, para as demais metodologias testadas, as sementes tratadas com Cruiser 350 FS apresentaram percentuais de plântulas normais inferiores, com uma diferença de menos 22 pontos percentuais para o substrato areia. Esse efeito positivo do fungicida/inseticida Standak Top, com o ingrediente ativo piraclostrobina + tiofanato metílico + fipronil foi objeto de estudo, evidenciando que o produto não afetou negativamente o percentual germinativo e sobrevivência das plântulas de trigo, apresentando porcentagem superior para germinação e vigor (Pereira et al., 2019). Ainda para cultura do trigo, constatou-se sob o uso da piraclostrobina, maior atividade antioxidante e menor síntese de etileno (Grossman et al., 1999).

Também na Tabela 3, o percentual de plântulas normais para sementes sem tratamento (testemunha) obteve percentual inferior as demais para os substratos rolo de papel e rolo de papel + areia. Para o substrato rolo de papel verificou-se que não ocorreram diferenças significativas entre os tratamentos, para o teste de germinação. Contudo, sementes tratadas com Fortenza 600 FS e Standak top atingiram percentuais acima de 80\% de plântulas normais. Bem como para a cultura do trigo, na cultura do milho a molécula de fungicida piraclostrobina propicia maior produtividade, aumento na massa seca de parte aérea e índice de área foliar, constatando ainda que quando é utilizada com tiofanato metílico há um efeito sinérgico nas características citadas (Lima et al., 2009). 
Tabela 3. Teste de germinação (testemunha e sementes tratadas) na temperatura constante de $25^{\circ} \mathrm{C}$ e utilização de quatro substratos, rolo de papel; rolo de papel + areia; rolo de papel + vermiculita; areia.

\begin{tabular}{|c|c|c|c|c|c|}
\hline Substratos & Testemunha & $\begin{array}{c}\text { Fortenza } 600 \\
\text { FS }\end{array}$ & Standak top & $\begin{array}{c}\text { Cruiser } 350 \\
\text { FS }\end{array}$ & Maxim XL \\
\hline Rolo de papel & $76 \mathrm{~A}$ & $80 \mathrm{~A}$ & $85 \mathrm{~A}$ & $78 \mathrm{~A}$ & $79 \mathrm{~A}$ \\
\hline \multicolumn{6}{|l|}{$\mathrm{CV}(\%) \quad 7,46$} \\
\hline $\begin{array}{c}\text { Rolo de papel }+ \\
\text { areia }\end{array}$ & $69 B$ & $77 \mathrm{AB}$ & $82 \mathrm{~A}$ & $81 \mathrm{~A}$ & $70 B$ \\
\hline \multicolumn{6}{|l|}{$\mathrm{CV}(\%) \quad 7,92$} \\
\hline $\begin{array}{c}\text { Rolo de papel + } \\
\text { vermiculita }\end{array}$ & $71 \mathrm{BC}$ & $72 \mathrm{BC}$ & $86 \mathrm{~A}$ & $67 \mathrm{C}$ & $83 \mathrm{AB}$ \\
\hline \multicolumn{6}{|l|}{$\mathrm{CV}(\%) 10,65$} \\
\hline Areia & $65 \mathrm{~A}$ & $54 \mathrm{~A}$ & $61 \mathrm{~A}$ & $59 \mathrm{~A}$ & $64 \mathrm{~A}$ \\
\hline $\mathrm{CV}(\%) 14,65$ & & & & & \\
\hline
\end{tabular}

*Na linha, médias seguidas da mesma letra maiúscula não diferem significativamente entre si, pelo teste de Tukey, a $5 \%$ de probabilidade. Fonte: Autores.

O índice de velocidade de germinação (IVG) descrito por Maguire (1962) tem sido o teste mais empregado para avaliar a velocidade de germinação. As avaliações das plântulas são realizadas diariamente, à mesma hora, a partir do dia em que surgem as primeiras plântulas normais. O procedimento descrito de avaliação prossegue até o dia da última contagem estabelecido pelas Regras para Análise de Sementes (Brasil, 2009). Ao fim do teste, com os dados diários do número de plântulas normais, calcula-se o índice de velocidade de germinação e quanto maior o valor obtido subentende-se maior velocidade de germinação e maior vigor (Nakagawa, 1994). No presente estudo a germinação dos tratamentos se estabeleceu em média no sexto dia após a semeadura, sendo a segunda e última contagem realizada ao sétimo dia. Desse modo, a avaliação do teste de germinação corresponde àquela proposta para o gênero Zea, presente nas Regras para Análise de Sementes (Brasil, 2009).

Com base nos valores médios do índice de velocidade de germinação (Tabela 4), verifica-se que sementes tratadas com o inseticida Fortenza 600 FS e o fungicida/inseticida Standak top quando combinadas com o substrato rolo de papel apresentam maior velocidade de germinação de sementes de Zea mays L. grupo saccharata, não diferindo significativamente entre si. A combinação do rolo de papel sob temperatura de $25^{\circ} \mathrm{C}$ é mencionada como a combinação responsável pelos maiores índices de velocidade de germinação de diversas espécies (Oliveira et al., 2013; Silva et al., 2017).

O resultado obtido para sementes tratadas com Standak top corrobora com os resultados do teste de germinação em porcentagem de plântulas normais. Entretanto, ainda que a velocidade seja satisfatória para sementes tratadas com o inseticida Fortenza 600 FS, seus resultados quanto ao percentual de plântulas normais variam conforme o substrato. Resposta que pode ser atribuída a sanidade dessas sementes, pois a mesma interage com os atributos de natureza genética, física e fisiológica das sementes (Marcos Filho, 2015). Por se tratar de um inseticida, as sementes permanecem suscetíveis à colonização de fungos fitopatogênicos, tornando possível observá-los durante as análises realizadas, seja no teste de germinação, evidenciado na Figura 1, como na execução do "blotter test" mostrado na Figura 2, afetando também o desenvolvimento da parte aérea das plântulas, que quando comparadas àquelas provenientes de sementes tratadas com fungicida mostram-se menos desenvolvidas.

Para o substrato rolo de papel + areia foi constatado que as plântulas de sementes tratadas com o inseticida Fortenza 600 FS se desenvolveram melhor, parte aérea e sistema radicular, ainda que na presença de fungos. Provavelmente pelo substrato areia reunir características necessárias de um bom substrato para germinação, tais como porosidade e esterilidade. 
Uma boa porosidade permite o movimento de água e ar no substrato, favorecendo a germinação. Para que isso ocorra, as sementes não necessitam de nutrientes, mas apenas de sua hidratação e aeração para que se procedam as reações que induzam à formação de parte aérea e raízes.

Figura 1. Sementes, testemunha e tratadas quimicamente com o uso de inseticidas, submetidas à incubação pelo método "Blotter Test".

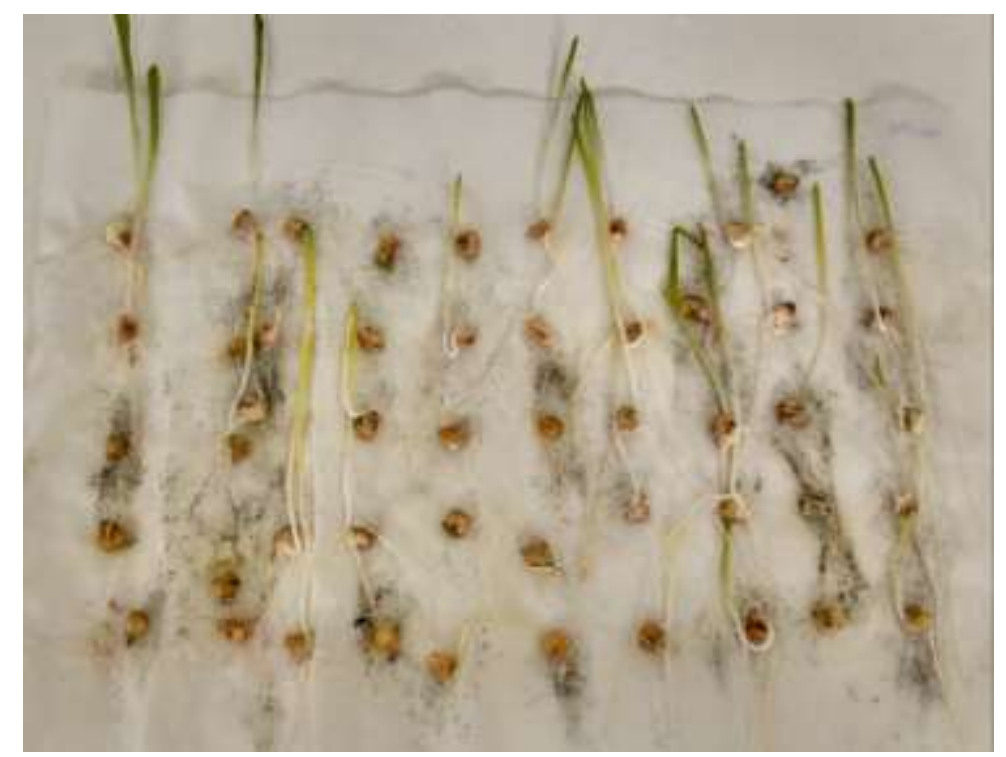

Fonte: Autores.

Por sua vez, sementes tratadas quimicamente com o uso de fungicidas, mostram-se aparentemente sadias, impossibilitando a visualização de micélios sem o auxílio de microscópio, conforme visualizamos na Figura 2.

Figura 2. Sementes, tratadas quimicamente com o uso de fungicida e fungicida + inseticida, submetidas à incubação pelo método "Blotter Test".

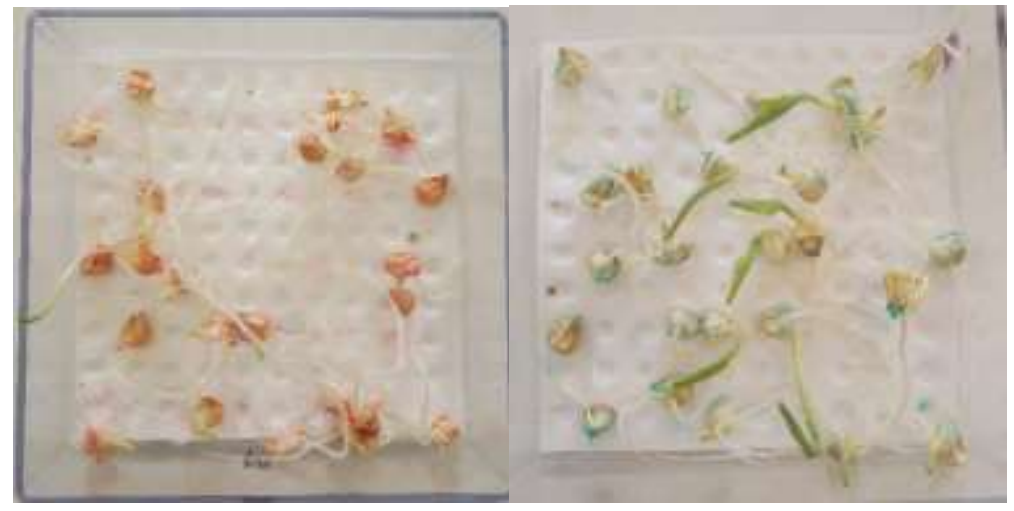

Fonte: Autores.

Sementes tratadas com o inseticida Cruiser 350 FS e o fungicida Maxim XL não diferiram significativamente das demais (Tabela 4). A testemunha, por sua vez, obteve uma diferença significativa de sua média quando comparada àquelas tratadas com Fortenza 600 FS e Standak top. Embora tendo demonstrado inferioridade às sementes tratadas no parâmetro velocidade de germinação, as sementes sem tratamento (sem adição de fungicida e/ou inseticida), sob temperatura de exposição constante de $25^{\circ} \mathrm{C}$, apresentaram um percentual de germinação acima de $65 \%$ para todos os tratamentos/substratos 
(Tabela 4). Apesar desse teste nem sempre conseguir medir diferenças existentes entre lotes ou amostras, pode indicar valores semelhantes para lotes com comportamentos distintos (Brown \& Mayer, 1986).

Tabela 4. Índice de velocidade de germinação (testemunha e sementes tratadas) em rolo de papel.

\begin{tabular}{cccccc}
\hline & Testemunha & Fortenza 600 FS & Standak top & Cruiser 350 FS & Maxim XL \\
\cline { 2 - 6 } Rolo de Papel & $16,97 \mathrm{~B}$ & $19,00 \mathrm{~A}$ & $19,01 \mathrm{~A}$ & $17.57 \mathrm{AB}$ & $17,87 \mathrm{AB}$ \\
\hline $\mathrm{CV}(\%) 7,04$ & & & & & \\
\hline
\end{tabular}

*Na linha, médias seguidas da mesma letra maiúscula não diferem significativamente entre si, pelo teste de Tukey, a $5 \%$ de probabilidade. Fonte: Autores.

O teste de primeira contagem de germinação (Tabela 5), que corresponde ao percentual de sementes germinadas no quarto dia após a instalação do teste, diferenciou os tratamentos em três classes de vigor. Em que, o tratamento 3 foi classificado como de alto desempenho, tratamentos 2, 5 e 4 de desempenho intermediário e o tratamento 1 (testemunha) de baixo desempenho, para sementes testadas no substrato rolo de papel; tratamentos 3 e 4 classificados como de alto desempenho, tratamentos 2 e 1 de desempenho intermediário e o tratamento 5 de baixo desempenho, para sementes testadas no substrato rolo de papel + areia; tratamento 3 classificado como de alto desempenho, tratamentos 5 e 2 de desempenho intermediário e tratamentos 1 e 4 de baixo desempenho, para sementes testadas no substrato rolo de papel + vermiculita. Para o substrato areia não foi realizada a primeira contagem.

Os dados obtidos na primeira contagem expressam o vigor das plântulas quando comparados a última contagem. Com exceção do substrato rolo de papel + areia para sementes tratadas com Maxim XL, os dados obtidos em relação aos demais substratos e seus respectivos tratamentos permanecem consistentes, pois os mesmos tratamentos com bom desempenho na primeira contagem do teste de germinação apresentaram alta porcentagem de germinação na última contagem.

Tabela 5. Primeira contagem de germinação (testemunha e sementes tratadas) ao quarto dia na temperatura constante de $25^{\circ} \mathrm{C}$ e utilização de quatro substratos, rolo e papel; rolo de papel + areia; rolo de papel + vermiculita; areia.

\begin{tabular}{|c|c|c|c|c|c|}
\hline Substratos & Testemunha & $\begin{array}{c}\text { Fortenza } 600 \\
\text { FS }\end{array}$ & Standak top & Cruiser 350 FS & Maxim XL \\
\hline Rolo de papel & $70 \mathrm{C}$ & $78 \mathrm{AB}$ & $80 \mathrm{~A}$ & $73 \mathrm{BC}$ & $75 \mathrm{ABC}$ \\
\hline \multicolumn{6}{|l|}{ CV (\%) 7.02} \\
\hline $\begin{array}{c}\text { Rolo de papel + } \\
\text { areia }\end{array}$ & $67 \mathrm{BC}$ & $74 \mathrm{AB}$ & $81 \mathrm{~A}$ & $79 \mathrm{~A}$ & $60 \mathrm{C}$ \\
\hline \multicolumn{6}{|l|}{$\mathrm{CV}(\%) 8.83$} \\
\hline $\begin{array}{c}\text { Rolo de papel + } \\
\text { vermiculita }\end{array}$ & $67 \mathrm{C}$ & $68 \mathrm{BC}$ & $84 \mathrm{~A}$ & $64 \mathrm{C}$ & $76 \mathrm{AB}$ \\
\hline CV (\%) 9.18 & & & & & \\
\hline
\end{tabular}

*Na linha, médias seguidas da mesma letra maiúscula não diferem significativamente entre si, pelo teste de Tukey, a 5\% de probabilidade. Fonte: Autores. 
A emergência das sementes pode sofrer alterações por fatores internos, relacionados à longevidade, vigor e também por fatores externos, como água, temperatura e oxigênio (Carvalho \& Nakagawa, 2012). Conceituado como o conjunto de atributos que confere à semente a capacidade para germinar, emergir e resultar rapidamente em plântulas normais, o vigor influencia, geralmente, no estabelecimento de uma população de plantas adequada sobre variações de condições ambientais (Marcos Filho, 2017). Contudo, para cultura do milho doce, estudos revelam um efeito prejudicial do açúcar na germinação de suas sementes, afetando a emergência à campo, a qual não apresenta correlação positiva com o teor de açúcar em sementes secas (Pairochteerakul, 2018).

Resultados obtidos no presente estudo reafirmam a perda de poder germinativo das sementes de milho doce quando semeadas à campo, expostas a variações de condições ambientais. No entanto, não podemos afirmar que somente os teores de amido e açúcar total das sementes de milho doce causam perdas tão severas na germinação e o vigor das plântulas à campo, pois vários fatores, como genótipo, doença de solo, fator ambiental, armazenamento de sementes (Parera et al., 1995), peso e tegumento da semente (Adetimirin et al., 2006), todos têm um efeito, bem como a soma e interações entre fatores.

Os resultados das análises de variância dos testes de emergência a campo e índice de velocidade de emergência relacionam-se positivamente (Tabela 6), apesar de ambas não apresentarem acurácia de suas médias quando comparadas as médias obtidas nos testes de germinação e índice de velocidade de germinação, bem como para as médias obtidas na primeira contagem de germinação, que demonstrou maior vigor para testemunha independente do substrato utilizado, e médias $\geq 60 \%$ para todos tratamentos $\mathrm{x}$ substratos (Tabela 5), discordando dos resultados obtidos no teste de emergência, no qual todos tratamentos apresentaram vigor $\leq 40 \%$ e maior vigor para sementes tratadas com o fungicida/inseticida Standak top e para testemunha, respectivamente (Tabela 6).

A piraclostrobina, um dos ingredientes ativos do produto comercial Standak top, apresenta efeito fisiológico nas culturas, promove o aumento de biomassa e produtividade, até mesmo em plantas sadias, atua na nitrato redutase, enzima que catalisa o primeiro passo na assimilação do nitrato $\left(\mathrm{NO}^{3-}\right)$ e aumenta o ponto de compensação do $\mathrm{CO}$, que garante maior eficiência na fotossíntese (Köhle et al., 2002), além de que se trata de uma mistura contendo o inseticida Fipronil do grupo pirazol, e os fungicidas Piraclostrobina do grupo das estrobilurinas e Tiofanato Metílico do grupo dos benzimidazois, seletivo para as culturas indicadas, de modo de ação protetora, sistêmica, de contato e ingestão, protegendo as sementes e plântulas contra o ataque de pragas, e fungos no período inicial de desenvolvimento da cultura. Enquanto os demais produtos utilizados classificam-se apenas como fungicida ou inseticida.

Tabela 6. Emergência e Índice de Velocidade de Emergência (testemunha e sementes tratadas) em canteiros.

\begin{tabular}{|c|c|c|c|c|c|}
\hline Análise & Testemunha & Fortenza 600 FS & Standak top & Cruiser 350 FS & Maxim XL \\
\hline Emergência & $39 \mathrm{~A}$ & $35 \mathrm{~B}$ & $40 \mathrm{~A}$ & $32,5 \mathrm{~B}$ & 26,5 \\
\hline \multicolumn{6}{|l|}{ CV $(\%) 4.72$} \\
\hline IVE & 7.61AB & $6.83 \mathrm{BC}$ & $8.18 \mathrm{~A}$ & $6.53 \mathrm{C}$ & 5.21 \\
\hline
\end{tabular}

*Na linha, médias seguidas da mesma letra maiúscula não diferem significativamente entre si, pelo teste de Tukey, a 5\% de probabilidade. Fonte: Autores.

Os patógenos encontrados nas sementes apresentaram variações na diversidade e incidência. Foram observados 7 gêneros de fungos, nas 3 amostras analisadas, que incluem a testemunha, sementes tratadas com o fungicida/inseticida Standak top e sementes tratadas com o fungicida Maxim XL. Foi observada a presença de Rhizopus stolonifer, Alternaria sp. e Fusarium sp. em todas amostras analisadas. Contudo, sementes tratadas com o fungicida Maxim XL, de contato de amplo 
espectro com atividade residual, apresentaram redução significativa do gênero Rhizopus stolonifer, enquanto o fungicida/inseticida Standak top, de ação protetora, sistêmico, de contato e ingestão, obteve melhor resposta ao gênero Fusarium sp. (Tabela 7).

Ainda foram encontrados, associados às sementes de milho doce, os fungos Aspergillus flavus, Aspergillus niger, Alternaria sp., Curvularia sp., e Trichoderma sp., porém em baixa incidência, não atingindo $10 \%$ das amostras, como verificase nos dados obtidos (Tabela 7). A presença de fungos como Alternaria sp. evidenciam o transporte e a associação de patógenos causadores de doenças, em diversas culturas, causando prejuízos econômicos, seja em grãos ou sementes (Kobayasti $\&$ Pires, 2011). Associados, esses e outros fungos podem acelerar o processo de deterioração.

Tabela 7. Porcentagem de incidência de fungos fitopatogênicos, em sementes de milho doce (testemunha e sementes tratadas).

\begin{tabular}{llll}
\hline & Testemunha & Standak top & Maxim XL \\
\hline Rhizopus $s$. & $60 \%$ & $30 \%$ & $1 \%$ \\
Aspergillus $f$. & $7 \%$ & - & $2 \%$ \\
Aspergillus $n$. & - & - & $2 \%$ \\
Alternaria sp. & $0,5 \%$ & $1,5 \%$ & $0,5 \%$ \\
Curvularia sp. & - & $0,5 \%$ & - \\
Trichoderma sp. & - & - & $0,5 \%$ \\
Fusarium sp. & $11 \%$ & $2 \%$ & $7 \%$ \\
\hline
\end{tabular}

Fonte: Autores.

A análise de patologia de sementes foi realizada para todos tratamento, porém os resultados de incubação para sementes tratadas com inseticidas (Fortenza 600 FS e Cruiser 350 FS) foram excluídos da tabela, por se tratarem de sementes tão suscetíveis ao ataque de fungos fitopatogênicos quanto à testemunha. Não obstante, cabe ressaltar que além dos 7 gêneros encontrados nas 3 amostras citadas acima (Tabela 7), sementes tratadas somente com o inseticida Fortenza 600 FS tiveram 17,5\% das sementes contaminadas por fungos de armazenamento do gênero Penicilium sp., e constatouse também a presença do gênero Chaetomium spp., porém com baixo percentual.

\section{Considerações Finais}

O substrato mais indicado para instalação do teste de germinação em milho doce depende da classe agronômica do produto e ingrediente ativo usado no tratamento de sementes.

Os substratos alternativos rolo de papel + areia e rolo de papel + vermiculita foram promissores na condução do teste de germinação em sementes de milho doce tratadas.

O substrato areia em bandejas não é indicado para realização do teste de germinação em sementes de milho doce.

O produto comercial Standak top obteve efeito positivo e superior aos demais para tratamento de sementes de milho doce em todas análises realizadas.

Com exceção do gênero Rhizopus, as sementes de milho doce avaliadas apresentaram baixa frequência de fungos fitopatogênicos. O produto Maxim XL foi eficaz no controle do gênero Rhizopus stolonifer, praticamente eliminando-o, enquanto o produto Standak top obteve maior eficácia no controle do gênero Fusarium sp. 


\section{Agradecimentos}

A Coordenação de Aperfeiçoamento de Pessoal de Nível Superior (CAPES) pela concessão de bolsa.

\section{Referências}

Adetimirin, V. O., Kim, S. K., \& Szczech, M. (2006). Factors associated with emergence of shrunken-2 maize in Korea. The Journal of Agricultural Science, $144(1), 63-68$.

Aziz, M. S., Nawaz, R., Haider, N., Rehman, Z. U., Aamir, A. H., \& Imran, M. (2019). Starch composition, antioxidant potential, and glycemic indices of various varieties of Triticum aesitivum L. and Zea mays L. available in Pakistan. Journal Food Biochemis. 2019, $43(8)$, e12943.

Silva, R. B., Matos, V. P., Farias, S. G. G de., Sena, L. H de. M., \& Silva, D. Y. B de. O. (2017). Germinação e vigor de plântulas de Parkia platycephala Benth. em diferentes substratos e temperaturas. Revista Ciência Agronômica, 48(1), 142-150, 2017.

Bhatt, P. S., Yakadri, M., \& Sivalakshmi, Y. (2021). Influence of varying plant densities and nitrogen levels on yield attributes and yield of sweet corn. International Journal of Bio-Resource e Stress Management, 3(3), 169-172.

Brasil. (2009). Ministério da Agricultura, Pecuária e Abastecimento. Regras para análise de sementes. SAND/DNDV/CLAV.

Brown, R.F., Mayer, D.G. (1986). A critical analysis of Maguire"es germination rate index. Journal of Seed Technology, 10(2), 101-110.

Carvalho, N. M., \& Nakagawa, J. (2012). Sementes: Ciência, Tecnologia e Produção. (4nd ed.), FUNEP.

Cruz, C. A. (2014). Produtividade e rendimento industrial do milho doce irrigado em função de dose e parcelamento de nitrogênio. Dissertação na Ciências Agrárias e Veterinárias, Unesp.

Gomes Junior, F. G. (2009). Incidência de patógenos e vigor de sementes de milho doce submetidas a danos mecânicos. Summa Phytopathologica, 35(3), 179183.

Grossmann, K., Kwiatkowski, J., \& Caspar, G. (1999). Regulation of phytohormone levels, leaf senescence and transpiration by the strobilurin Kresoximmethyl in wheat (Triticum aestivum L.). Journal of Plant Physiology, 154, 805-808.

ISTA. (2011). International Seed Testing Association. International rules for seed testing. Procediment International Seed Testing.

Köhle, H. (2002). Physiological effects of the strobilurin fungicide F 500 on plants. In: Dehne, H. W. (Eds.). Modern fungicides and antifungal compounds III. Bonn: AgroConcept GmbH.

Lima, A. S., Raffatti, T. N., Juncos, M. C., Burbulban, T., \& Martikoski, L. (2009). Efeito fisiológico de fungicida pyraclostrobin e tratamento de semente na cultura do milho. Pesquisa aplicada e agrotecnologia, 2(3), 113-120.

Maguire, J. D. (1962). Speed of germination-aid in selection and evaluation for seedlings emergence and vigor. Crop Science, 2(1), $176-177$.

Marcos Filho, J. (2017). Conceituação do vigor de sementes em seus múltiplos aspectos. In: XX Congresso brasileiro de semente. ABRATES.

Oliveira, A. K. M. (2013). Effects of temperature on the germination of Diptychandra aurantiaca (Fabaceae) seeds. Acta Scientiarum. Agronomy, 35(2), 203208.

Oliveira, F. N., França, F. D., Torres, S. B., Nogueira, N. W., \& Freitas, R. M. O. (2016). Temperaturas e substratos na germinação de sementes de pereirovermelho (Simiragardneriana M.R. Barbosa \& Peixoto). Revista Ciência Agronômica, 47(4), 658-666.

PairochteerakuL, P., Jothityangkoon, D., Ketthaisong, D., Simla, S., Lertrat, K., \& Suriharn, B. (2018). Potchanee et al. Seed germination in relation to total sugar and starch in endosperm mutant of sweet corn genotypes. Agronomy, 8(12), 2-11.

Parera, C. A., Cantliffe, D. J., Rtoffella, P. J., \& Scully, B. T. (1995). Field emergence of shrunken-2 corn predicted by single- and multiple-vigor laboratory. Journal of the American Society for Horticultural Science, 120,(1), 128-132.

Pereira Filho, I. A., \& Teixeira, F. F. (2016). O cultivo do milho-doce. Informativo técnico, Embrapa. MAPA.

Pereira, F. S. (2019). Tratamento de sementes sobre a germinação, o vigor e o desenvolvimento do trigo. Revista de Ciências Agroveterinárias, 18(3), 395399.

Yang, T. R., Hu, J.G., Yu, Y. T., LI, G.K., Guo, X.B., Li, T., \& Liu, R. H. (2018). Comparison of phenolics, flavonoids, and cellular antioxidant activities in ear sections of sweet corn (Zea mays L. saccharata Sturt). Journal Food Process, 43, e13855. 